The doctor-patient relationship

\title{
The drama of being a doctor
}

\section{R Persaud}

\section{Perhaps it is time to get out the acting manuals and rewrite the scripts so everybody gets a good role and no one ends up the villain of the piece.}

\author{
All the world's a stage, \\ And all the men and women merely \\ players: \\ They have their exits and their \\ entrances, \\ And one man in his time plays many \\ parts, \\ (William Shakespeare As You Like It \\ II.vii)
}

O ne comparatively unusual and perhaps uncomfortable way of thinking about the practice of medicine is that the consultation with a patient is a kind of theatre. The doctor and the patient have their roles, actually encapsulated by the medical sociologist's Talcott Parson's conceptualisation of the "sick role" -which the patient plays. ${ }^{.}$What part the doctor adopts has oddly received less attention from medical sociology, partly perhaps because the profession is resistant to the notion that sometimes the consultation entails playacting.

Talcott Parsons idea of the sick role in the 1950s was the first theoretical concept that explicitly concerned medical sociology. In contrast with the biomedical model, which pictures illness as a mechanical malfunction or a microbiological invasion, Parsons described the sick role as a temporary, medically sanctioned form of deviant behaviour.

Parsons used ideas from Freud's psychoanalytic theories to shed light on the social and psychological forces involved in episodes of sickness. The Freudian concepts of transference and counter-transference led Parsons to see the doctor/patient relationship as analogous to that of the parent and child. The idea that a sick person has conflicting drives both to recover from the illness and to continue to enjoy the "secondary gains" of attention and exemption from normal duties also stems from a Freudian model of the structure of the personality.

Since Parson's work other issues like "breaking bad news" have received much similar attention in the academic medical literature, but the basic notion that often doctors are indeed enacting lines from a script-they are playing a part that entails them not actually being true to what they are really feeling from moment to moment in a consultationis something that is rarely openly acknowledged, far less discussed.

Doctors often have to appear sympathetic or caring or involved when they could be far from feeling these things. While doctors admit this privately in consultations with psychiatrists (like myself), this is an emotion issue that otherwise they dare not speak its name within the profession. Could it be that playacting is in itself not a bad way of proceeding, but the key issue is how we engage with this vital part of what we do when we interact with patients. If we were always totally authentic when with patients, the strain of this might be incompatible with a viable career, plus it's not something patients themselves might desire either.

But there is a basic tension between the values of truth and science as imparted in medical training, and the notion of the consultation as basically an act of theatre that requires dramatic skills from the doctor, as the lead player. This model however lends itself to the useful idea that physicians need to learn certain emotional control and manipulation techniques with which actors would be familiar, to best cope with the psychological demands of patients.

One way of thinking about medicine, and particularly the stress of working in this career, is that doctors conduct two basic interactions in their daily jobsthey interact with "things" like technology such as an MRI scanner, and they interact with people. There is accumulating psychological evidence that much of the stress of medical work arises from interactions with people rather than things. ${ }^{2}$

It has long been said that postindustrial societies have a workforce that is moving relentlessly through a key transition-from manufacturing to service oriented work. This basically means that we are increasingly doing jobs where we don't deal so much with "things", like components on an assembly line, but more with other people. But what hasn't been realised fully is that having to constantly deal with people rather than "things", often brings a unique constellation of stresses, which the modern workplace or workforce doesn't seem at all prepared for.

Much of medical training for example, at one level seems to be focused on how to deal with "things" like a liver or a liver function test result, rather than how to cope with people, like patients and colleagues. This lack of training on how to deal with people could mean doctors are ill equipped when it comes to this vital part of their jobs, and this explains much of their subsequent stress. Note also that doctors are often dealing with people precisely at one of the most difficult times in their lives and so are at their most complex in terms of the psychological handling they require.

For example, some recent psychological research has established that a large part of the stress of working in the rapidly expanding sector of call centres is the strain of having to be remorselessly cheerful to callers. ${ }^{2}$ The so called "have a nice day" syndrome is about the "emotional labour" we have to do on a daily basis to keep ourselves appearing fairly reasonable to all around us, no matter how ragged we are really feeling, plus to smilingly absorb the difficulties of dealing with problematic customers, when you really want to wring their necks.

Psychologists are now increasingly recognising that this "emotional labour" may in fact be more mentally taxing than the more physical toil required of us in the past.

Psychologists use the term surface level emotional labour to capture the basic fact that a large part of dealing with people at work is basically "faking it" or pretending to emotions we basically don't actually feel, like feigning interest, sympathy, or understanding. ${ }^{3}$

But now new research by occupational psychologists Celeste Brotheridge and Alicia Grandey at the University of Pennsylvania in the USA has found that the more your job requires you to fake emotions, the more likely you are to become emotionally detached from those around you at work, also more detached from your own emotional state (you may not realise how depressed and upset you truly are) and the greater therefore your future job dissatisfaction. ${ }^{3}$

It seems that the two key emotional labour tasks required of doctors, are to hide negative emotions, plus to display positive feelings even when these are not residing within one. Psychologists believe that constantly hiding the deep 
hatred you feel for colleagues and difficult patients might be fairly stressful in itself, but having to go beyond this and portray positive emotions when you really feel the opposite must be even worse and surely pushes you nearer to "burnout". ${ }^{4}$

Burnout is the state of mind you achieve as a result of stressful work when you feel spent, so suffering from emotional exhaustion, plus you then display a detached attitude towards others, perhaps behaving like a psychopath towards them rather than genuinely caring. As a result of this you experience a low sense of effectiveness at work and therefore diminished personal accomplishment. ${ }^{5}$

Burnout is strongly linked to a tendency to leave the job, hating your work, and lowered performance at the clinic. It's also possible to see that this personal detachment in jobs that require high levels of caring like nursing and medicine could even be positively dangerous-resulting in such negative behaviour towards patients or clients that they end up suffering grievously as a result. ${ }^{6}$

Jobs that are thought to be particularly prone to burnout are those where you have to be relentlessly positive, and so the caring professions like medicine, nursing, social work, and teaching, where there is a large amount of personal interaction that requires deep personal attention and concern and therefore perhaps a huge amount of emotional labour. $^{6}$

However, the very latest research on the link between burnout and emotional labour by Brotheridge and Grandey suggests that the key issue isn't the acting you have to do at work, but it's the way you try to act that predicts whether you are going to suffer from burnout or not. Indeed they found that in some jobs it was the high emotional labour that actually predicted greater sense of personal accomplishment. ${ }^{3}$

The key seems to be whether at work you are performing emotional labour requiring "superficial" acting or "deep" acting.

Superficial acting is where you just pretend to be pleased to see someone while deep down you are plotting how to cut the brake cables of their car. Deep acting on the other hand is where you try to change your basic attitudes towards the people you interact with by changing your thoughts and deeper feelings, so as to try and make them more positive to those around you.

So for example if you are in child care work it could be that many of the young children you are looking after eventually upset you, but you make a conscious effort to remain positive and not snap at them because deep down you believe that this is a better emotional state to be in than one of irritability towards young children.

The key finding of Brotheridge and Grandey was that those who seemed to engage in "deep" acting actually found jobs that demanded high levels of emotional labour more personally rewarding. ${ }^{3}$

You set about deep acting by using the self same techniques Hollywood actors who take their job seriously go about researching a part. If for example a star is to play the part of a cop, he will go and hang out with real policemenimmerse himself in that world as it were-and adopt a role model who he observes closely and tries to understand his motivation. So you need to find a role model or hang out with those who model the kind of behaviour you are trying to adopt. It could be there are people at the reception desk who are relentlessly good natured no matter how awkward the patient-what drives them? How do they see the world?

Another key technique that actors use is to develop a sympathy for the part they have to play no matter how distasteful it might be-to do this they create a back story that helps generate compassion when this might be a difficult emotion to access. So they will think of an exasperating patient who they have to be nice to as someone who may be themselves having a very bad day or could be dealing with terrible problems in their own personal life. This back story helps the actor develop the right attitude to the part they have to part.

So the answer seems to be that if it's the people at work who you feel are driving you round the bend, you need to find a way of emotionally reacting to them by changing your deeper attitudes, and as a result you will actually begin to enjoy your work.

Then as a result when you pick up your award or "oscar" for outstanding performance at work you can genuinely start your thank you speech by saying "...I should like to thank the academy..." because you will have got to the podium as a result of "deep" acting.

Many doctors will be uncomfortable with the model of the consultation as an act of theatre, and yet the accoutrements are there for all to see-for example, there is dressing up (wearing white coats and other uniforms) the purpose of which is often to delineate roles and enact scripts. Perhaps the tension lies in the key issue of what the primary goal is when patients are seen. If it is to be totally and brutally honest at all times with patients about how we are feeling then this raises the question as to whether patients really desire this. What patients want from doctors in terms of their desire for an authority figure, a trusted confidante, and a friend are often in conflict with each other. They want, for example, availability, and yet this conflicts with rival demands from other patients of a popular doctor. ${ }^{7}$

If what patients want from us entails an impossible combination of characteristics then it's time to get out the acting manuals and rewrite the scripts so everybody gets a good role and no one ends up the villain of the piece, which is the danger if doctors refuse to take part.

Postgrad Med J 2005;81:276-277. doi: $10.1136 /$ pgmi.2004.023796

Correspondence to: Dr R Persaud, The Maudsley Hospital, Westways Clinic, $49 \mathrm{St}$ James Road, Croydon CR9 2RR, UK; r.persaud@iop.kcl.ac.uk

\section{REFERENCES}

1 Parsons T. The cocial system. London: Routledge Keegan Press, 1951.

2 Pugliesi K. The consequences of emotional labor: effects on work stress, job satisfaction, and wellbeing. Motivation and Emotion 1999;23:125-54.

3 Brotheridge C, Grandey A. Emotional labor and burnout: comparing two perspectives on "people work". Journal of Vocational Behavior 2002;60:17-39.

4 Gross J, Levenson R. Hiding feelings: the acute effects of inhibiting negative and positive emotions. J Abnorm Psychol 1997; 106:95-103.

5 Jackson SE, Turner JA, Brief AP. Correlates of burnout among public service lawyers. Journal of Occupational Behavior 1987;8:339-49.

6 Maslach C, Schaufeli WB. Historical and conceptual development of burnout. In: Schaufeli WB, Maslach C, Marek T, eds. Professional burnout: recent developments in theory and research. Washington, DC: Taylor and Francis, 1993:1-16.

7 Hochschild AR. Emotion work, feeling rules, and social structure. American Journal of Sociology 1979;85:551-75. 